\title{
Roadside bombs and routes to life: The experience of
}

\section{Turkey}

\section{Sebahattin Çelik}

General Surgery Department Van Yuzuncu Yol University Faculty of Medicine Van/Turkey

\begin{abstract}
Injuries caused by roadside improvised explosive devices (IEDs) have recently been on the increase in Turkey. The aim of the present study is to evaluate the types of injuries sustained by victims of IEDs, and the pre-hospital/inter-hospital handling of patients transported to a Level 1 trauma center following roadside bombings.

Data were obtained from the registry of an earlier multi-centric prospective study designed to evaluate injuries caused by high kinetic energy weapons. Here, we retrospectively analyze injuries resulting from roadside bombs. All patients in the registry from August 2015 to May 2016 who were victims of roadside explosions were included. Patient demographics, injury severity scores (ISS), wound types, and transfusions need s were recorded and outcomes (length of hospital stay and mortalities) were evaluated.

Of 390 patients injured by high kinetic energy weapons, 51 were wounded by roadside bombs (an estimated hospital incidence of $13 ; 1 \%$ ). Fourteen separate incidents were observed (an average of 3.6 patients per incident). Of these patients, 8 were civilian and 43 were security personnel. The mean injury rate to multiple body regions was $71.8 \%$ and the mortality rate was $15.7 \%$. Pneumothorax and pulmonary contusion were the leading pathologies in terms of lethality. Vehicular accidents were frequently observed as causes of tertiary blast injuries. Twelve patients were transported to hospital who did not have physical injuries

Our experience has shown that a roadside bomb not only causes an explosion, but also possibly a vehicular accident, burns, and, severe psychological trauma as well.
\end{abstract}

Key Words: Roadside bombs, pre-hospital care, IED, terrorism

\section{Introduction}

An improvised explosive device (IED) is a kind of homemade bomb frequently deployed in roadside bombings and not used in conventional warfare. IEDs consist of explosives (which may be conventional explosives such as artillery, or a number of other materials) connected to a detonator. These bombs are usually hidden along the edges or in the ditches of main roads and are detonated when a vehicle passes by. In general, all explosives produce their detrimental effects in one of several well-defined ways $(1,2)$. However, roadside bombs differ from other explosives in that their victims are most often in vehicles, which presents not one but two potential dangers: blast and blunt traumas.

In civilian settings, IEDs have increasingly been used as roadside bombs by various terrorist organizations in recent years. Israel in particular has frequently experienced such incidents, (3-5) as has Afghanistan.(6). With the rise in terror-related activities, physicians will increasingly be required to treat victims of mass casualty incidents, requiring a broadening of their existing skills and specialized knowledge of the various mechanisms of injuries.

In Turkey, terrorist acts have been an unfortunate reality for many years. As a neighbor of Syria with its ongoing civil war Turkey has become one of the most vulnerable countries in the Middle East. The most recent uprising, which began in 2015, has been particularly devastating, causing extensive loss of life and injuries to young civilians.

This study describes in detail injuries caused by roadside bomb explosions and the chaotic processes of triage and transporting victims to hospitals where they can receive optimal care. The aim of this study is to increase familiarity with the unique characteristics of roadside bombs and associated secondary and tertiary injuries.

\section{Materials and Methods}

On August 15, 2015 a multi-centric prospective observational study, registered in an international 
clinical trial registry system (Registration number/date: ISRCTN49138604 /September 8, 2015), was started by the High Kinetic Energy Weapons Study Group (7). Data for the present study was obtained from the above-mentioned prospective study and analyzed retrospectively. Ethical approval for this study was granted by the Ethics Committee of Yuzuncu Y1 University Faculty of Medicine (date: 27.10.2015 number: 01).

Setting: Four tertiary care centers (two university hospitals, one military academy hospital, and one training and research hospital) participated in this study. All four of these hospitals meet the criteria for a Level 1 trauma center. Victims who were transported from either the scene of the incident or from a Level 2 or 3 trauma center were evaluated at the emergency departments of those hospitals.

Patients: A detailed description of the inclusion and exclusion process has been published elsewhere(7). Briefly, only patients who were victims of a roadside bombing were included in this study. In addition to patients who were wounded, the study included those not injured but otherwise affected by the bombing who were therefore transported to hospital. Patients who were wounded by gunshot or by explosives other than roadside bombs were excluded.

Measurement of Variables: Patient vital signs were checked and recorded by the emergency department upon patient arrival. The trauma region was divided into five anatomical regions: head/neck/face/spinal cord, thorax, extremities, abdomen, and skin/soft tissue. After all injuries were evaluated, an Abbreviated Injury Score (AIS) was estimated(8) and then, based on this score, Injury Severity Score (ISS was calculated using the method described by Baker et al(9).

Additional trauma was defined as any injury that occurred simultaneous with or subsequent to the primary injury (ies). Included in this category are vehicular accidents, occurring as a result of a bombing or during transport of the patient, and burns that cover more than $1 \%$ of the total body area. Historically, patterns of injury caused by explosions have been classified as primary, secondary or tertiary $(10,11)$. In recent years, an additional category, quaternary blast injuriesoccasionally termed "miscellaneous"- has been described(12). Based on this classification, the additional traumas which we encountered were tertiary and quaternary injuries.

Measurement of Outcomes: Information regarding patient mortality and LOS were collected from the registry systems of the primary hospitals.

Mortality: It was defined as death resulting from a wound that occurred during hospitalization or within 180 days of the initial injury. Death which occurred during CPR after arrival in the hospital emergency department was also considered an inhospital death. Mortalities that occurred on scene were excluded, as the chaotic conditions that obtained at the scenes hindered accurate assessment of the number of deaths.

Length of Hospital stay (LOS): It was calculated as the number of days from the date of first admission until the discharge date.

Statistical Analysis: Data were analyzed by using SPSS (IBM SPSS Statistics for Windows, Version 20.0. Armonk, NY: IBM Corp.). The assumptions of normality were violated for all continuous variables. Therefore, descriptive statistics for these variables were reported as median, minimummaximum, and Interquartile range (IQR). Descriptive statistics for the categorical or nominal variables were presented as frequency and percent. The Chi-square test (Pearson chi square, Fischer exacts, or likelihood ratio, where appropriate) was used to determine relationships between categorical or nominal variables. The Mann-Whitney $U$ test was used to compare median values of LOS, arrival time, and ISS between two different modes s of transport.

\section{Results}

During the 9-month patient enrolment period, 14 roadside bombings occurred in Eastern and Southeastern Turkey. Following these incidents, a total of 51 patients were transported to hospital by one of three modes of transport (ambulance, helicopter, and private vehicle). Injury profiles for these 14 incidents, including their ISS and mortality frequencies, are summarized in (Table $1)$.

As seen in Table 1 , a plurality of patients $(n=12)$ did not sustain any physical injuries. These patients were either transported to hospital out of "fear of being injured", as a result of being very close to the scene of the incident, or else were passengers in an attacked vehicle but nonetheless remained uninjured. Extremities were the region of the body most affected (22 cases). After extremities, the most affected regions of the body were as follows; thorax (16 cases), maxillofacial region (12 cases), cranium (10 cases), vertebra (6 cases), pelvis (5 cases) abdominal region (4 cases), and soft tissue/skin (2 cases). 
As seen in Table-1, generally patients were young and minimum 2 persons maximum 6 persons were affected in each incident. We observed that if there was a pulmonary pathology (pneumothorax or hemothorax etc.) in a patient it was likely there would be a similar pathology in one of the other patients in same incident. And again it was more likely to had vertebral or pelvic fractures in more than one patient in same incident.

Following the incidents, $37.3 \%$ of the victims $(n=19)$ were first transported to a Level 2 or Level 3 trauma care center (e.g., local state and private hospitals), and subsequently to a Level 1 trauma center (Table 2). The other 32 wounded (62.7\%) were initially transported directly to a Level 1 trauma care center (primarily university hospitals). The median ISS was 10 (min.-max.=1-36, $I Q R=15)$ for patients who were first transported to Level 2 or 3 trauma center. Patients who were directly transported to a Level I trauma center had a median ISS of 11.5 (min- $\max =1-59, \mathrm{IQR}=24)$ $(\mathrm{p}=0.171)$ (Figure 1).

All mortalities were observed in patients who were directly transported to Level 1 trauma centers. Out of 8 mortalities, 7 cases were wounded in 3 or more anatomical regions, while 1 case sustained only a cranial injury (intracranial parenchymal hematoma). Hypovolemic shock was present in 6 mortalities when the victims arrived at the Level 1 trauma center. None of these 6 mortalities underwent blood transfusion during transport. CPR was performed on 3 patients upon arrival at hospital. Five deaths occurred after hospitalization. The median ISS was 49 (min.max.: 25-59, IQR =23) for patients who died and 9 (min.-max.:1-36, IQR=15) for those who survived $(\mathrm{p}<0.001)$.

The most frequently encountered tertiary mechanism of injury was vehicular accidents and resulting blunt injuries. Burns were observed on 2 patients as quaternary injuries (Table 2).

Despite the fact that all attacks were directed at security personnel (both soldiers and police), 8 civilians $(15.7 \%)$ were also injured. Out of 14 roadside bombs, 9 were hidden in roads frequently used by civilians (on main roads between cities). The other five bombs were located in remote areas (on roads between villages). The 8 civilians were all injured on main roads, and one of died as a result of his injuries.

The total transport time was dependent on the route was used. For patients transported directly from the scene to a Level 1 trauma care center, the median transport time was 90 minutes. However, the median transport time was 240 minutes for patients transported from a secondary local hospital (Table 2; $\mathrm{p}=0.001$ ). When transport times for both routes were considered together, the total median transport time was 90 minutes.

Although LOS was longer for those transported directly from the scene (Table 2), the difference was not statistically significant $(\mathrm{p}=0.174)$.

\section{Discussion}

In the present study, 51 patients who were injured or otherwise affected by 14 roadside bombs were evaluated in one of four different Level 1 trauma care centers in terms of pre-hospital and interhospital care. Since the invasion of Iraq in March 2003, the insurgency that has arisen to fight the coalition forces has killed and wounded thousands of U.S. soldiers(13). Most of these deaths were caused by IEDs. Also known as roadside bombs, IEDs have increasingly been used especially in recent decades in Turkey especially in rural areas.

The fourteen incidents that occurred in Eastern and Southeastern Turkey during the study period yielded 51 patients, an average of 3.6 victims per bombing. A study by Peleg et al. (14) reported that "explosion victims are usually part of a mass casualty event and arrive at the hospital as part of a group while gunshot wound patients are more often injured in sporadic events and arrive as individuals. Our experience aligns with that of Peleg et al., and we would add that in the case of roadside bombs, in our experience patient numbers generally do not exceed hospital capacity. This may be due to the fact that roadside bombs typically target a specific vehicle (mainly security vehicles), and fortunately not all bombs are successful in their aims. Furthermore, almost all roadside bombs are hidden away from public places, which lessen their detrimental effects.

The median ISS was 10 (serious injury) when all injured patients were considered together and 49 for the subgroup of mortal patients $(n=8)$. Because reliable information concerning on-scene fatalities was not available, in this study the total number of actual deaths from roadside bombs cannot be calculated. It should therefore be kept in mind that the fatalities reported in this study are in-hospital mortalities only. Twelve patients who were not physically wounded were transported to hospital because they were at the scene of an incident or in an attacked vehicle. Although these physically unaffected patients were evaluated as "normal" for the purposes of the present study, in our estimation they should be considered "psychologically traumatized" due to

East J Med Volume:23, Number:1, January-March/2018 
the fear and panic they experienced that led them to believe that they could have been injured. Interestingly, a number of patients had quite different ISS values from those of other patients affected by the same incidents (from no physical injury to a median ISS of 49). This shows that the same incident may cause critical injuries in some while leaving others only slightly injured or even uninjured.
In our estimation they should be considered "psychologically traumatized" due to the fear and panic they experienced that led them to believe that they could have been injured. Interestingly, a number of patients had quite different ISS values from those of other patients affected by the same incidents (from no physical injury to a median ISS of 49 ). A study from Israel reported that $29.3 \%$ of hospitalized suicide bombing victims suffered severe to critical (ISS $\geq 16$ ) injuries(3).

Table 1. Characteristics of patients and injuries according to incidents that caused by roadside bombs

\begin{tabular}{|c|c|c|c|c|c|}
\hline Incidents & $\begin{array}{c}\text { Patients } \\
\text { number/mean age }\end{array}$ & $\begin{array}{c}\text { accompanying } \\
\text { event }\end{array}$ & Injury type & $\begin{array}{l}\text { ISS (from mild } \\
\text { to severe) }\end{array}$ & Mortality \\
\hline 1 & $3 / 29.33$ & Vehicular accident & $\begin{array}{l}\text { No injury } \\
\text { Lower ext. tissue loss } \\
\text { Scapula fracture and } \\
\text { pulmonary contusion }\end{array}$ & $1 / 4 / 18$ & No \\
\hline 2 & $3 / 27.00$ & Vehicular accident & $\begin{array}{c}\text { Thoracal vertebra and } \\
\text { nasal fracture } \\
\text { Lumbar vertebra fracture } \\
\text { and pneumothorax } \\
\text { Pneumothorax, liver } \\
\text { laceration and lower } \\
\text { extremity fracture }\end{array}$ & $5 / 10 / 29$ & In third patient. \\
\hline 3 & $5 / 25.20$ & Vehicular accident & $\begin{array}{l}\text { No injury in four patient } \\
\text { Lower ext. tissue loss in } \\
\text { one patient }\end{array}$ & $1 / 4$ & No \\
\hline 4 & $6 / 25.83$ & Vehicular accident & $\begin{array}{c}\text { No injury in three patient } \\
\text { Thoracal vertebra and } \\
\text { nasal fracture } \\
\text { Pelvic Fracture } \\
\text { Pneumothorax, liver } \\
\text { laceration and lower } \\
\text { extremity fracture }\end{array}$ & $1 / 5 / 16 / 29$ & No \\
\hline 5 & $2 / 33.00$ & Vehicular accident & $\begin{array}{c}\text { Pelvic Fracture } \\
\text { Lumbar vertebra fracture } \\
\text { and pneumothorax }\end{array}$ & $13 / 16$ & No \\
\hline 6 & $5 / 28.20$ & $\begin{array}{c}\text { Vehicular accident } \\
\text { and Burn }\end{array}$ & $\begin{array}{c}\text { No injury } \\
\text { Eye injury } \\
\text { Eye and hand injuries } \\
\text { Cranial bone fracture and } \\
\text { maxillofacial injury } \\
\text { Intracranial parenchymal } \\
\text { hematoma pneumothorax, } \\
\text { hemothorax and upper } \\
\text { extremity fracture }\end{array}$ & $1 / 4 / 10 / 13 / 48$ & In fifth patient. \\
\hline 7 & $5 / 19.40$ & Non & $\begin{array}{c}\text { Eye and hand injuries } \\
\text { Hemothorax, } \\
\text { pneumothorax, small and } \\
\text { large bowel perforation, } \\
\text { mesenteric bleeding, lower } \\
\text { and upper extremity } \\
\text { fractures, and peripheral } \\
\text { arterial lacerations } \\
\text { Intracranial parenchymal } \\
\text { hematoma } \\
\text { Epidural hematoma, eye } \\
\text { injury, pneumothorax, } \\
\text { hemothorax, and upper } \\
\text { extremity tissue loss } \\
\text { Subarachnoid hematoma } \\
\text { and upper extremity tissue } \\
\text { loss }\end{array}$ & $10 / 25 / 36 / 50 / 59$ & $\begin{array}{l}\text { In third, fourth } \\
\text { and fifth } \\
\text { patients. }\end{array}$ \\
\hline
\end{tabular}


Table 1. Continue

\begin{tabular}{|c|c|c|c|c|c|}
\hline Incidents & $\begin{array}{c}\text { Patients } \\
\text { number/mean age }\end{array}$ & $\begin{array}{c}\text { accompanying } \\
\text { event }\end{array}$ & Injury type & $\begin{array}{l}\text { ISS (from mild } \\
\text { to severe) }\end{array}$ & Mortality \\
\hline 8 & $5 / 24.00$ & Vehicular accident & $\begin{array}{c}\text { No injury } \\
\text { Lower extremity fracture } \\
\text { in two patients. } \\
\text { Intracranial parenchymal } \\
\text { hematoma } \\
\text { pneumothorax, } \\
\text { hemothorax, and upper } \\
\text { extremity fracture } \\
\text { Epidural hematoma, eye } \\
\text { injury, pneumothorax, } \\
\text { hemothorax, and upper } \\
\text { extremity tissue loss }\end{array}$ & $1 / 9 / 48 / 59$ & $\begin{array}{l}\text { In fourth and } \\
\text { fifth patients. }\end{array}$ \\
\hline 9 & $2 / 27.50$ & Non & $\begin{array}{l}\text { Lumbar vertebra fracture } \\
\text { and pneumothorax } \\
\text { Maxillofacial and pelvic } \\
\text { fracture }\end{array}$ & $10 / 17$ & No \\
\hline 10 & $4 / 33.75$ & $\begin{array}{c}\text { Vehicular accident } \\
\text { and Burn }\end{array}$ & $\begin{array}{c}\text { Eye injury } \\
\text { Pelvic Fracture } \\
\text { Scapula fracture and } \\
\text { pulmonary contusion } \\
\text { Cranial bone fracture and } \\
\text { maxillofacial injury }\end{array}$ & $4 / 13 / 16 / 18$ & No \\
\hline 11 & $3 / 35.67$ & Non & $\begin{array}{c}\text { Maxillofacial and pelvic } \\
\text { fracture } \\
\text { Pulmonary contusion, } \\
\text { pneumothorax, } \\
\text { hemothorax, and hand } \\
\text { injury } \\
\text { Intracranial parenchymal } \\
\text { hematoma }\end{array}$ & $17 / 25 / 25$ & No \\
\hline 12 & $2 / 31.50$ & Vehicular accident & $\begin{array}{c}\text { No injury } \\
\text { Hand damage }\end{array}$ & $1 / 1$ & No \\
\hline 13 & $3 / 20.33$ & Vehicular accident & $\begin{array}{c}\text { Hand damage } \\
\text { Lumbar vertebra fracture } \\
\text { and pneumothorax } \\
\text { Subarachnoid hematoma } \\
\text { and upper extremity } \\
\text { tissue loss }\end{array}$ & $1 / 13 / 34$ & No \\
\hline 14 & $3 / 34.00$ & Vehicular accident & $\begin{array}{c}\text { No injury } \\
\text { Pulmonary contusion, } \\
\text { pneumothorax, } \\
\text { hemothorax, and hand } \\
\text { injury } \\
\text { Hemothorax, } \\
\text { pneumothorax, small and } \\
\text { large bowel perforation, } \\
\text { mesenteric bleeding, } \\
\text { lower and upper extremity } \\
\text { fractures, and peripheral } \\
\text { arterial lacerations }\end{array}$ & $1 / 17 / 50$ & In third patient. \\
\hline
\end{tabular}

ISS: Injury Severity Score, ext: Extremity 
Table 2. Patient demographics, transport type, transport time, and outcomes according to route used

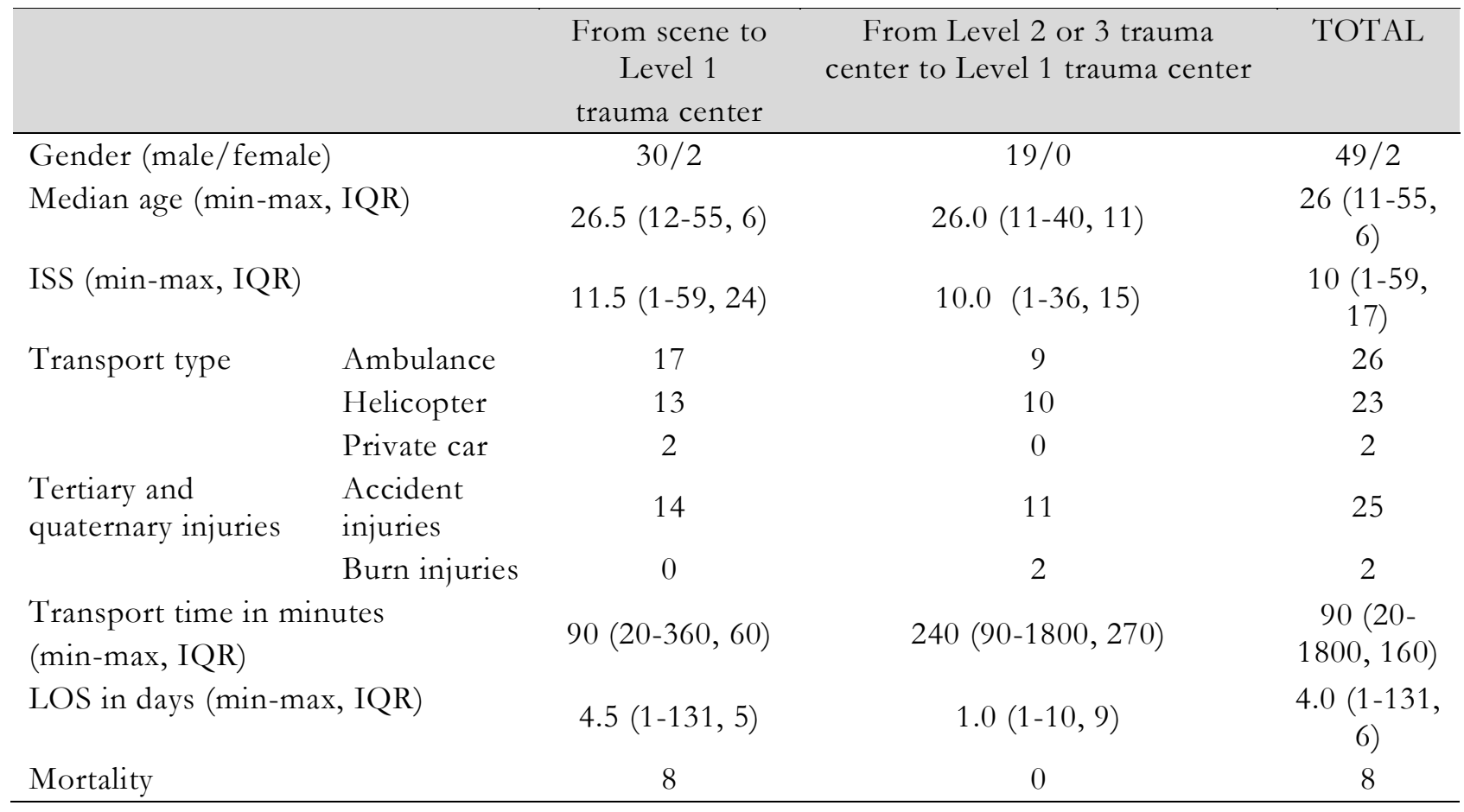

Fig. 1. Distribution of injury severity scores according to transport route. Patients who were transported from the scene to Level 1 trauma care centers are labeled as "Level 1", while those transported from another hospital to a Level-1 trauma center are labeled as “ Level 2 or 3".

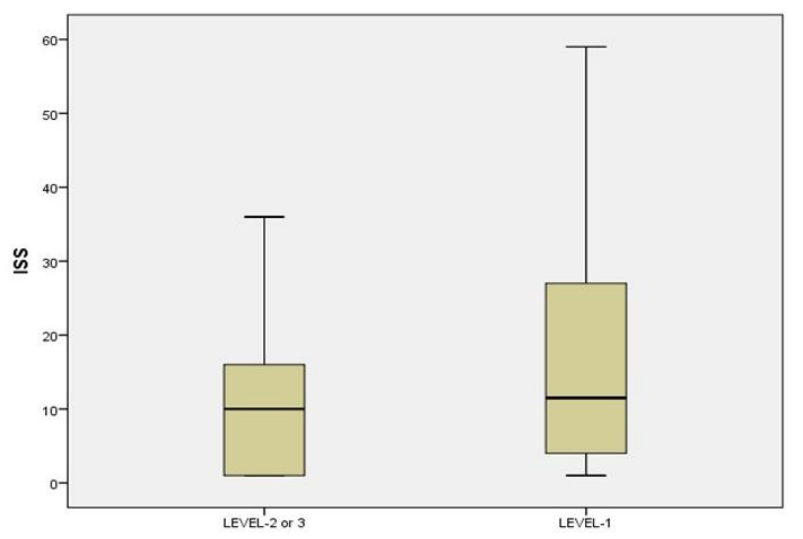

Golan et al. (15) found that explosions adjacent to a vehicle (in this case, a bus) were lesser severity than explosions inside a bus. Thus, the vehicle itself may protect those inside the vehicle. But as learned from history superiority sometimes may be inferiority due to some circumstantial factors (e.g. rolling). Similarly, in the case of roadside bombs, we observed that while the vehicles themselves may protect their passengers, keeping them safer than those outside the vehicle, when rolling occurs due to the forces of the blast or loss of control of the vehicle, passengers could be in greater danger.
In the present study, out of 51 patients, 25 patients were injured as a result of crashes or rolling of vehicles, and 2 patients experienced severe burns because they could not escape from the burning vehicle. Pelvic fracture (3 cases) and intracranial parenchymal hematoma (2 cases) were also observed in patients involved in vehicular accidents. Unfortunately, experience has taught us the painful lesson that a roadside bomb not only causes an explosion, but also may result in a vehicular accident, burns, and in most cases, severe psychological trauma as well.

As expected given the mechanisms of blast injuries, we found that generally more than two regions of the body were affected by roadside bombings. Isolated injuries included intracranial parenchymal hematoma in 2 cases, pelvic fracture in 3 cases, eye injury in 2 cases, and lower extremity fracture with tissue loss in 4 cases. The remaining 28 patients sustained multiple injuries. In a study from Israel, Bala et al. (4) reported that injuries to multiple regions of the body $(\geq 3)$ occurred in $85.7 \%$ of patients in the blast group. After excluding those who sustained no injuries (12 patients), the percentage of patients in our study with injuries to multiple regions was determined to be $71.8 \%$. When compared with the results of the study by Bala et al., the low rate of the present study might be due to the advantages conferred by being in a well-protected army vehicle, as most of our patients were soldiers. The 
thorax was the most affected region of the body after extremity injuries, which were relatively less severe in terms of lethality compared to pulmonary pathologies. Pneumothorax and pulmonary contusion were the leading pathologies resulting in death. Thus, our results confirm the fact that the pulmonary system is at elevated risk for primary blast injuries because of its considerable air-tissue surface area $(1,16)$. Our results were similar to those reported by Willy et al. (6) in their study which analyzed injury patterns and the mechanisms thereof in soldiers of the coalition forces in Afghanistan.

In Turkey, following an incident, first the Emergency Control Center (a national medical organization concerned with all types of emergency situations) is informed via the free emergency telephone number 112 . The basic level response involves a standard ambulance staffed by either two paramedics or by one paramedic and one doctor. These ambulances are equipped to provide basic treatment/life support and to transport the patient to hospital. Once the scene of the incident has been secured, the medical team can begin to assess the condition of the victims. The vast majority of paramedics and doctors in Turkey have only basic life support training, and ambulances have only basic life support equipment and the minimal necessities for patient transport. In chaotic circumstances and during ongoing conflicts, the sole objective of the emergency medical team is to transport patients to the nearest safe hospital. Triage in the true sense of the word begins after arrival to a safe hospital (in Turkey, generally state hospitals). At these hospitals, most patients are directed to tertiary hospitals which have Level 1 trauma facilities. Patients who are military or security personnel are then usually transferred to military hospitals (which also have Level I trauma centers) after they are stabilized. As observed in the present study, a significant number of patients who could have been treated in a Level 2 or 3 trauma center received unnecessary inter-hospital transport, resulting in a waste of time and resources. MacKenzie et al. (17) reported that "the observed (unadjusted) case fatality rate in the hospital was lower among patients treated at trauma centers (Level 1 centers) than among patients treated at non-trauma centers. We are in full agreement with MacKenzie et al.; moreover, we believe that by employing correct triage at the scene, the decreased Level 1 patient load will enhance the effectiveness of Level 1 trauma centers. A good example of pre-hospital care of trauma patients and effective trauma team organization is found in
Israel $(2,18)$. There, mobile intensive care units and multi-casualty response vehicles, which are essentially mobile equipment stores used during prolonged multi-casualty incidents, respond to terror events. This approach may be effective in responding to roadside bomb incidents in Turkey, as it allows for a significant number of victims to be treated with simple and appropriate interventions on-scene.

In conclusion, the lessons we have learned from our experience with roadside bombs in Turkey can be summarized as follows: Most of the time, IEDs are hidden in main, frequently used roads in rural part of country. Although their effects may be devastating, the number of unsuccessful attacks is not low. There may be a dramatic difference in injury severity between one victim and another who are both exposed to the same blast. Blunt traumas (especially pelvic fractures) were frequently observed in cases where the explosion led to a vehicular accident. Appropriate selection of a trauma center and accurate triage on-scene may decrease the level of chaos experienced and the numbers of unnecessary inter hospital transfers.

Contributors: SC designed the study, collected data and drafted the article.

Declaration of interest: I declare no competing interest.

\section{Funding: None}

Acknowledgement: The author would like to thank the following members of the High Kinetic Energy Weapons Working Group: Recep Dursun, Abdurrahman Aycan, Hayriye Gönüllü, Cihan Adanaş, Mehmet Eryılmaz, Edip Gönüllü, M. Edip Akyol, M. Sait Aktan, Çağhan Pekşen, Sıddık Keskin, Cağfer Güloğlu. And thank to Kerri Maki for editing.

\section{References}

1. Wolf SJ, Bebarta VS, Bonnett CJ, Pons PT, Cantrill SV. Blast injuries. Lancet 2009; 374: 405415.

2. Mayo A, Kluger Y. Terrorist bombing. World J Emerg Surg 2006; 1: 33

3. Aharonson-Daniel L, Klein Y, Peleg K, Itg. Suicide bombers form a new injury profile. Ann Surg 2006; 244: 1018-1023.

4. Bala M, Rivkind AI, Zamir G, et al. Abdominal trauma after terrorist bombing attacks exhibits a unique pattern of injury. Ann Surg 2008; 248: 303-309.

5. Mintz Y, Shapira SC, Pikarsky AJ, et al. The experience of one institution dealing with terror: 
the El Aqsa Intifada riots. Isr Med Assoc J 2002; 4: 554-556.

6. Willy C, Hauer T, Huschitt N, Palm HG. "Einsatzchirurgie"-experiences of German military surgeons in Afghanistan. Langenbecks Arch Surg 2011; 396: 507-522.

7. Celik S, Dursun R, Aycan A, et al. The dynamics of prehospital/hospital care and modes of transport during civil conflict and terrorist incidents. Public Health 2017; 152: 108-116.

8. Rating the severity of tissue damage. I. The abbreviated scale. JAMA 1971; 215: 277-280.

9. Baker SP, O'Neill B, Haddon W, Jr., Long WB. The injury severity score: a method for describing patients with multiple injuries and evaluating emergency care. J Trauma 1974; 14: 187-196.

10. Mellor SG. The pathogenesis of blast injury and its management. Br J Hosp Med 1988; 39: 536539.

11. Zuckerman S. Experimental study of blast injuries to the lungs. The Lancet 1940; 236: 219-224.

12. Kluger $\mathrm{Y}$, Nimrod A, Biderman P, Mayo A, Sorkin P. The quinary pattern of blast injury. American journal of disaster medicine 2006; 2: 21 25.
13. Bokel J. An Asymmetric Threat Invokes Strategic Leader Initiative: The Joint Improvised Explosive Device Defeat Organization. The Industrial College of the Armed Forces, National Defense University; 2007.

14. Peleg K, Aharonson-Daniel L, Stein M, et al. Gunshot and explosion injuries: characteristics, outcomes, and implications for care of terrorrelated injuries in Israel. Ann Surg 2004; 239: 311 318.

15. Golan R, Soffer D, Givon A, Peleg K, Group IT The ins and outs of terrorist bus explosions: Injury profiles of on-board explosions versus explosions occurring adjacent to a bus. Injury 2014; 45: 39-43.

16. Leibovici D, Gofrit ON, Stein M, et al. Blast injuries: bus versus open-air bombings--a comparative study of injuries in survivors of open-air versus confined-space explosions. Journal of Trauma and Acute Care Surgery 1996; 41: 1030-1035.

17. MacKenzie EJ, Rivara FP, Jurkovich GJ, et al. A national evaluation of the effect of trauma-center care on mortality. New England Journal of Medicine 2006; 354: 366-378.

18. Ellis DY, Sorene E. Magen David Adom-The EMS in Israel. Resuscitation 2008; 76: 5-10. 